\title{
Analisis Tarif Pesawat Rute Banda Aceh - Jakarta Berdasarkan Total Operating Cost, Ability To Pay dan Willingness To Pay
}

\author{
Siti Nadya Putri ${ }^{1}$ Yusria Darma ${ }^{2}$ Noer Fadhly ${ }^{3}$ \\ 1,2,3 Jurusan Teknik Sipil, Universitas Syiah Kuala, Banda Aceh 23111, Indonesia \\ Email: sitinadya41@gmail.com
}

\begin{abstract}
There has been an increase in aircraft fares since November 2018 and the application of paid baggage to several airlines since January 2019, has caused a decrease in the number of passengers. The main issues to be discussed in this study were determining the ideal aircraft fare based on Total Operating Cost, Ability To Pay, and Willingness To Pay. This research consisted of data collection, namely primary data and secondary data. Primary data was obtained by distributing questionnaires to passengers of the Banda Aceh - Jakarta route using the Revealed Preference technique. While the secondary data was obtained by conducting interviews with airlines as a basis for determining the Total Operating Cost (TOC) of an aircraft. Based on the research conducted, the value of the fare based on the TOC low cost airlanes with a load factor that was assumed to be 75\% was Rp1.263.000. The value of the fare based on the TOC full service airlanes with a load factor that was assumed to be 75\% was Rp1.556.000. The amount of fare based on Ability To Pay (ATP) Citilink passenger was Rp2.341.000; The ATP of Lion Air passenger was amounting to Rp2.367.000; The ATP of Batik Air passenger was amounting to Rp3.279.000; and the ATP of Garuda Indonesia passenger was amounting to Rp3.099.000. The amount of fare value based on Willingness To Pay (WTP) of Citilink passenger was Rp1.357.000; The WTP of Lion Air passenger amounting to Rp1.369.000; The WTP of Batik Air passenger was amounting to Rp1.653.000; and The WTP of Garuda Indonesia passenger was amounting to Rp1.652.000.
\end{abstract}

Keyword: Total Operating Cost, Ability To Pay, Willingness To Pay, Revealed Preference

\begin{abstract}
Abstrak
Terjadinya kenaikan tarif pesawat sejak bulan November 2018 dan penerapan bagasi berbayar pada beberapa maskapai penerbangan sejak Januari 2019 menimbulkan menurunnya jumlah pengguna pesawat. Pokok permasalahan yang akan dibahas dalam penelitian ini adalah menentukan tarif pesawat terbang yang ideal berdasarkan, Total Operating Cost, Ability To Pay, dan Willingness To Pay. Penelitian ini terdiri dari pengumpulan data yaitu data primer dan data sekunder. Data primer diperoleh dengan cara menyebarkan kuesioner kepada pengguna pesawat terbang rute Banda Aceh - Jakarta menggunakan teknik Revealed Preference. Sedangkan data sekunder diperoleh dengan melakukan wawancara terhadap maskapai penerbangan sebagai dasar untuk menentukan Total Operating Cost (TOC) pesawat terbang. Berdasarkan penelitian yang dilakukan didapatkan besaran nilai tarif berdasarkan TOC maskapai penerbangan bertarif rendah dengan load factor yang diasumsikan 75\% adalah sebesar Rp1.263.000. Besaran nilai tarif berdasarkan TOC maskapai penerbangan layanan penuh dengan load factor yang diasumsikan 75\% adalah sebesar Rp1.556.000. Besaran nilai tarif berdasarkan Ability To Pay (ATP) pengguna pesawat Citilink sebesar Rp2.341.000; ATP pengguna pesawat Lion Air sebesar Rp2.367.000; ATP pengguna pesawat Batik Air sebesar Rp3.279.000; dan ATP pengguna pesawat Garuda Indonesia sebesar Rp3.099.000. Besaran nilai tarif berdasarkan Willingness To Pay (WTP) pengguna pesawat Citilink sebesar Rp1.357.000; WTP pengguna pesawat Lion Air sebesar Rp1.369.000; WTP pengguna pesawat Batik Air sebesar Rp1.653.000; dan WTP pengguna pesawat Garuda Indonesia sebesar Rp1.652.000.
\end{abstract}

Kata kunci: Total Operating Cost, Ability To Pay, Willingness To Pay, Reveal Preference

\section{Pendahuluan}

Terjadinya kenaikan tarif pesawat sejak bulan November 2018 dan penerapan bagasi berbayar pada beberapa maskapai penerbangan sejak Januari 2019 menimbulkan turunnya jumlah pengguna pesawat. Hal ini menyebabkan sebagian pengguna pesawat lebih memilih menggunakan pesawat dengan rute luar negeri karena harganya relatif lebih murah dibandingkan dengan harga tiket pesawat domestik.

Journal of The Civil Engineering Student

Vol. 3. No. 1, April 2021, Halaman 22-28
Keputusan Menteri Nomor 106 Tahun 2019[1], menyatakan tarif batas atas rute Banda Aceh - Jakarta adalah sebesar Rp2.228.000 dan tarif batas bawah rute Banda Aceh - Jakarta adalah sebesar Rp780.000.

Data primer pada penelitian ini diperoleh dengan cara menyebarkan kuesioner dengan menggunakan teknik Revealed Preference. Data yang diperoleh dari penelitian ini menggunakan sampel acak berstrata dengan 
memperlihatkan tingkatan dalam populasi (stratified random sampling). Pengumpulan data sekunder diperoleh dengan melakukan wawancara terhadap pihak maskapai penerbangan untuk mendapatkan data-data yang menjadi dasar untuk menentukan TOC, buku-buku, dan hasil penelitian terdahulu yang ada berhubungan dengan penelitian ini. Penelitian ini berlokasi di ruang tunggu Bandara Sultan Iskandar Muda Aceh.

Penelitian ini memiliki tujuan untuk mengetahui karakteristik pengguna pesawat terbang rute Banda Aceh - Jakarta, menghitung Total Operating Cost pesawat terbang sehingga didapatkan tarif sesuai TOC, melakukan analisis terhadap Ability To Pay pengguna jasa pesawat sehingga didapatkan nilai tarif berdasarkan ATP dan melakukan analisis terhadap Willingness To Pay pengguna jasa pesawat sehingga didapatkan nilai tarif berdasarkan WTP. Ruang lingkup penelitian ini terkait dengan kapasitas penumpang pesawat rute Banda Aceh - Jakarta per hari dengan load factor sebesar 75\%, total operating cost yang diteliti adalah maskapai penerbangan bertarif rendah (low cost carrier) dan maskapai penerbangan layanan penuh (full service airlane).

\section{Tinjauan Kepustakaan}

\subsection{Total Operating Cost (TOC)}

Menurut Peraturan Menteri Perhubungan Nomor 20 Tahun 2019[2], biaya operasi pesawat udara terdiri dari Biaya Operasi Langsung atau Direct Operating Cost (DOC) dan Biaya Operasi Tak Langsung atau Indirect Operating Cost (IOC). Formula yang digunakan untuk menghitung Total Operating Cost adalah sebagai berikut: $T O C=D O C+I O C$

Direct Operating Cost merupakan seluruh biaya yang berhubungan langsung dengan operasional pesawat dan tergantung kepada jenis pesawat udara yang dioperasikan dan akan berubah untuk jenis pesawat yang berbeda. Direct operating cost ini dapat dikelompokkan menjadi:

A. Biaya operasi langsung tetap

1. Biaya penyusutan/sewa pesawat udara;

2. Biaya asuransi;

3. Biaya gaji tetap crew;

4. Biaya gaji tetap teknisi.

B. Biaya operasi langsung variable

1. Biaya pelumas;

2. Biaya bahan bakar;

3. Biaya tunjangan crew;

4. Biaya overhaul/pemeliharaan;

5. Biaya jasa kebandarudaraan;

6. Biaya jasa pelayanan navigasi penerbangan;

7. Biaya jasa ground handling penerbangan;

8. Biaya catering penerbangan.

Indirect Operating Cost merupakan biaya yang tidak hanya disebabkan oleh sesuatu yang dibiayai dan

Journal of The Civil Engineering Student Vol. 3. No. 1, April 2021, Halaman 22-28 sering disebut dengan biaya overhead. Indirect operating cost ini dapat dikelompokkan menjadi:

1. Biaya organisasi;

2. Biaya pemasaran/penjualan.

\subsection{Ability To Pay (ATP)}

Ability to pay adalah kemampuan masyarakat dalam membayar ongkos perjalanan yang dilakukannya. Julien[3], menyatakan dengan menggunakan metode household budget dapat dicari besaran ATP.

$\mathrm{ATP}_{\text {umum }}=$ It $\times \mathrm{Pp} \times \frac{\mathrm{Pt}}{\mathrm{Tt}}$.

Keterangan:

$\mathrm{ATP}_{\text {umum }}=\mathrm{ATP}$ umum responden $(\mathrm{Rp} /$ penumpang $)$

It $=$ Total pendapatan keluarga per bulan (Rp/kel/bulan)

$\mathrm{Pp} \quad=$ Persentase pendapatan untuk transportasi per bulan dari total penghasilan

$\mathrm{Pt} \quad=$ Persentase biaya transportasi yang digunakan untuk pesawat terbang per bulan

$\mathrm{Tt}=$ Total panjang perjalanan keluarga per bulan per trip (trip/kel/bulan)

\subsection{Willingness To Pay (WTP)}

Willingness to pay adalah kesediaan pengguna untuk mengeluarkan imbalan atas jasa yang diperolehnya. Pendekatan yang digunakan dalam analisis WTP didasarkan pada persepsi pengguna terhadap tarif dari jasa pelayanan angkutan umum tersebut. Menurut M. R. Permata[4], analisis WTP didasarkan pada persepsi pengguna terhadap tarif atas jasa pelayanan angkutan umum yang dipengaruhi oleh beberapa faktor, yaitu:

1. Kuantitas dan kualitas jasa transportasi;

2. Utilitas pengguna;

3. Penghasilan pengguna.

Nilai WTP masing-masing responden yaitu berupa nilai maksimum rupiah yang bersedia dibayarkan oleh responden untuk jasa pesawat terbang, diolah untuk mendapatkan nilai rata-rata (mean) dari nilai WTP tersebut, dengan rumus:

MWTP $=\frac{1}{n} \sum_{i=1}^{n} W T P i$

Keterangan:

MWTP = Rata-rata WTP

$\mathrm{n} \quad=$ Ukuran sampel

WTPi = Nilai WTP Maksimum responden ke i

\subsection{Hubungan Ability To Pay dan Willingness To Pay}

Dalam penentuan tarif angkutan sering terjadi ketidaksesuaian antara ATP dan WTP, ada beberapa kondisi yang mungkin terjadi yaitu:

1. ATP > WTP

Kondisi ini menunjukan bahwa kemampuan membayar lebih besar dari pada keinginan membayar 
jasa tersebut. Hal ini terjadi bila pengguna mempunyai penghasilan yang relatif tinggi tetapi utilitas terhadap jasa tersebut relatif rendah, kondisi ini disebut choiced riders.

\section{ATP $<\mathrm{WTP}$}

Kondisi ini menunjukkan keinginan pengguna untuk membayar jasa tersebut lebih besar dari pada kemampuan membayarnya. Hal ini memungkinkan terjadi bagi pengguna yang mempunyai penghasilan yang relatif rendah tetapi utilitas terhadap jasa tersebut sangat tinggi, sehingga keinginan pengguna untuk membayar jasa tersebut cenderung lebih dipengaruhi oleh utilitas, kondisi ini pengguna disebut captive riders.

3. $\mathrm{ATP}=\mathrm{WTP}$

Kondisi ini menunjukan bahwa antara kemampuan dan keinginan membayar jasa yang dikonsumsi pengguna tersebut sama, pada kondisi ini terjadi keseimbangan utilitas pengguna dengan biaya yang dikeluarkan untuk membayar jasa tersebut.

\section{$2.5 \quad$ Kualitas Jasa}

Menurut Lewis dan Booms dalam $\mathrm{R}$. Lupiyoadi[5], kualitas jasa adalah suatu ukuran yang menggambarkan sebaik apa penyediaan jasa dilakukan. Penyampaian kualitas jasa berarti pemberian kualitas jasa yang disesuaikan pada harapan pelanggan secara konsisten.

\subsubsection{Dimensi kualitas jasa}

Menurut Parasuraman, Zeithaml dan Berry dalam Julien[3], lima item kualitas jasa dari pendekatan SERVQUAL adalah sebagai berikut:

1. Reliability (Kehandalan)

2. Assurance (Jaminan)

3. Tangibles (Bukti Fisik)

4. Empathy (Empati)

5. Responsiveness (Ketanggapan)

\subsection{Uji Validitas dan Reliabilitas}

Julien[3], menyatakan uji validitas dilakukan untuk mengetahui sejauh mana suatu skala pengukuran dapat melakukan apa yang seharusnya dilakukan dan mengukur apa yang seharusnya diukur. Sedangkan uji reliabilitas dilakukan untuk mengetahui kehandalan suatu item pertanyaan dalam mengukur sesuatu.

Suatu pertanyaan dinyatakan valid apabila nilai $r$ hitung (Corrected Item-Total Correlation) pada tabel Item-Total Statistics lebih besar daripada nilai $\mathrm{r}$ tabel. Validitas eksternal juga hanya digunakan pada pertanyaan yang terdapat dalam kualitas pelayanan jasa (SERVQUAL). Cara yang dilakukan untuk uji validitas adalah dengan analisis item dengan menggunakan rumus koreasi pearson product moment:

$\mathrm{r}=\frac{\mathrm{n} \sum \mathrm{XY}-\left(\sum \mathrm{X}\right)\left(\sum \mathrm{Y}\right)}{\sqrt{\left[\mathrm{n} \sum \mathrm{X}^{2}-\left(\sum \mathrm{X}\right)^{2}\right]\left[\mathrm{n} \sum \mathrm{Y}-\left(\sum \mathrm{Y}\right)^{2}\right]}}$

Keterangan:

Journal of The Civil Engineering Student Vol. 3. No. 1, April 2021, Halaman 22-28 $\mathrm{r}=$ koefisien korelasi

$\mathrm{X}=$ nilai setiap pertanyaan

$\mathrm{Y}=$ nilai total seluruh butir pertanyaan untuk satu variabel

$\mathrm{n}=$ jumlah responden

S. Arikunto[6], menyatakan uji reliabilitas yang umum digunakan adalah analisa Alpha. Adapun pengujian dengan menggunakan koefisien Cornbach Alpha harus lebih besar atau sama dengan 0,6 yaitu nilai yang dianggap dapat menguji layak tidaknya kuesioner yang digunakan. Rumus yang digunakan adalah:

$\mathrm{r}=\frac{\mathrm{k}}{(\mathrm{k}-1)}\left[1-\frac{\sigma \mathrm{b}^{2}}{\sigma 1^{2}}\right]$

Keterangan:

$\mathrm{r} \quad=$ Reliabilitas instrument

$\mathrm{k} \quad=$ Banyaknya butir pertanyaan

$\sigma b^{2}=$ Jumlah varian butir

$\sigma 1^{2}=$ Jumlah varian total

Rumus untuk menghitung varian butir dan varian total adalah:

$\sigma \mathrm{b}^{2}=\frac{\mathrm{Jki}}{\mathrm{n}}-\frac{\mathrm{Jks}}{\mathrm{n}^{2}}$

$\sigma 1^{2}=\frac{\sum \mathrm{xt}}{\mathrm{n}}-\frac{\sum \mathrm{xt}^{2}}{\mathrm{n}^{2}}$

Keterangan:

Jki = Jumlah kuadrat seluruh butir

Jks = Jumlah kuadrat subjek

$\sum \mathrm{xt}=$ jumlah total jawaban responden

$\mathrm{n} \quad=$ Jumlah responden

\section{Metode Penelitian}

\subsection{Objek Penelitian}

Lokasi penelitian ini dilaksanakan pada Bandar Udara Sultan Iskandar Muda yang berada di Kecamatan Blang Bintang, Kabupaten Aceh Besar. Jumlah pengambilan sampel untuk data kuesioner terhadap responden penumpang pesawat terbang rute Banda Aceh - Jakarta di ruang tunggu Bandar Udara Sultan Iskandar Muda merujuk pada tabel Isaac dan Michael dengan menggunakan persen kelonggaran sebesar 5\% dan berdasarkan jumlah kapasitas penumpang pesawat rute Banda Aceh - Jakarta per hari.

Tabel 1 Kapasitas penumpang pesawat rute Banda Aceh - Jakarta per hari

\begin{tabular}{lccccc}
\hline Maskapai & $\begin{array}{c}\text { Jumlah } \\
\text { Penerb/ } \\
\text { Hari }\end{array}$ & $\begin{array}{c}\text { Tipe } \\
\text { Pesawat }\end{array}$ & $\begin{array}{c}\text { Jumlah } \\
\text { Kursi }\end{array}$ & $\begin{array}{c}\text { Total } \\
\text { pnp/mask } \\
\text { /hari }\end{array}$ & $\begin{array}{c}\text { Rute } \\
\text { Penerb }\end{array}$ \\
\hline Citilink & 1 & $\begin{array}{c}\text { Airbus } \\
\text { A320 }\end{array}$ & 180 & 180 & Indirect \\
Lion Air & 2 & $\begin{array}{c}737 \\
\text { Boeing }\end{array}$ & 189 & 378 & Indirect \\
Batik Air & 1 & Airbus & 156 & 156 & Direct
\end{tabular}


A320

\begin{tabular}{lccccc}
$\begin{array}{l}\text { Garuda } \\
\text { Indonesia }\end{array}$ & 2 & $\begin{array}{c}\text { Boeing } \\
737\end{array}$ & 162 & 324 & Direct \\
\hline TOTAL & & & & 1038 &
\end{tabular}

Sampel $=\frac{\text { Jmlh } \text { kapasitas pnp pada tiap maskapai } / \text { hari }}{\text { total penumpang } / \text { hari }} \times 261$

Sampel Citilink $=\frac{180}{1038} \times 261=45$ Sampel

Sampel Lion Air $=\frac{378}{1038} \times 261=95$ Sampel

Sampel Batik Air $=\frac{156}{1038} \times 261=39$ Sampel

Sampel Garuda $=\frac{324}{1038} \times 261=82$ Sampel

\subsection{Jenis Dan Sumber Data}

Data yang digunakan pada penelitian ini adalah data primer dan sekunder. Data primer didapatkan dengan menyebarkan kuesioner dan data sekunder didapatkan dengan melakukan wawancara.

\subsection{Teknik Pengumpulan Data}

Data primer pada penelitian ini diperoleh dengan cara menyebarkan kuesioner dengan menggunakan teknik Revealed Preference. Data yang diperoleh dari penelitian ini menggunakan sampel acak berstrata dengan memperlihatkan tingkatan dalam populasi (stratified random sampling). Data sekunder merupakan data yang diperoleh dengan melakukan wawancara terhadap pihak maskapai penerbangan untuk selanjutnya diolah dan dapat dipakai sebagai data pendukung.

\subsection{Teknik Analisis}

Analisis data dilakukan setelah pengujian validitas dan reliabilitas dilakukan dan data telah memenuhi kedua jenis uji tersebut. Analisis data pada penelitian ini dilakukan dengan menganalisis hasil yang telah diperoleh dari data primer dan data sekunder, sehingga didapatkan tarif berdasarkan total operating cost dengan menggunakan metode departemen perhubungan, tarif berdasarkan ability to pay (kemampuan untuk membayar) pesawat terbang dengan metode household budget, dan tarif berdasarkan willingness to pay (kemauan untuk membayar) dengan menggunakan metode persepsi responden.

\section{Hasil Dan Pembahasan}

\subsection{Uji Validitas}

Uji ini dilakukan dengan mengambil 261 sampel responden. Nilai $r_{\text {tabel }}$ dengan tingkat kesalahan yang

Journal of The Civil Engineering Student Vol. 3. No. 1, April 2021, Halaman 22-28 ditoleransi sebesar 5\% diperoleh sebesar 0,122. Selanjutnya nilai $r_{\text {tabel }}$ ini akan dibandingkan dengan nilai $r_{\text {hitung. }}$ Kriteria pengujian adalah, jika $r_{\text {hitung }} \geq r_{\text {tabel }}$, maka item pernyataan berkolerasi signifikan terhadap skor total (dinyatakan valid). Hasil uji validitas yang telah diolah melalui SPSS dapat dilihat pada tabel 2.

Tabel 2 Hasil Uji Validitas

\begin{tabular}{cccc}
\hline Butir & $\mathrm{R}_{\text {hitung }}$ & $\mathrm{R}_{\text {tabel }}$ & Penafsiran \\
\hline Q1 & 0.510 & 0.122 & Valid \\
Q2 & 0.580 & 0.122 & Valid \\
Q3 & 0.606 & 0.122 & Valid \\
Q4 & 0.752 & 0.122 & Valid \\
Q5 & 0.711 & 0.122 & Valid \\
Q6 & 0.693 & 0.122 & Valid \\
Q7 & 0.610 & 0.122 & Valid \\
Q8 & 0.792 & 0.122 & Valid \\
Q9 & 0.792 & 0.122 & Valid \\
Q10 & 0.745 & 0.122 & Valid \\
\hline
\end{tabular}

\subsection{Uji Reliabilitas}

Hasil Uji reliabilitas untuk butir-butir yang digunakan pada variabel kegiatan pemeliharaan dan kondisi pemeliharaan dapat dilihat pada tabel 3 .

Tabel 3 Hasil uji reliabilitas

\begin{tabular}{llll}
\hline Variabel & $\mathrm{N}$ & $\mathrm{C}_{\text {alpha }}$ & Penafsiran \\
\hline Kualitas jasa & 10 & 0.872 & Handal \\
\hline
\end{tabular}

\subsection{Karakteristik Responden}

Karakteristik responden yang dominan pada maskapai Citilink adalah pria sebesar $71 \%$, usia responden berkisar 30-39 tahun sebesar 35\%, status menikah sebanyak $84 \%$, pendapatan keluarga $\geq$ Rp5.000.000 sebesar 91\%, dan memiliki tujuan bisnis sebesar 34\%; karakteristik responden yang dominan pada maskapai Lion Air adalah pria sebesar 53\%, usia responden berkisar 20-29 tahun sebesar 29\%, status menikah sebesar $61 \%$, pendapatan keluarga $\geq$ Rp5.000.000 sebesar 78\%, dan memiliki tujuan bisnis sebesar 31\%; karakteristik responden yang dominan pada maskapai Batik Air adalah pria sebesar 69\%, usia responden berkisar 40-49 tahun sebesar 28\%, status menikah sebanyak 68\%, pendapatan keluarga $\geq$ Rp5.000.000 sebesar 74\%, dan memiliki tujuan lainnya sebesar 51\%; dan karakteristik responden yang dominan pada maskapai Garuda Indonesia adalah pria sebesar $80 \%$, usia responden berkisar 30-39 tahun sebesar 38\%, status menikah sebanyak $84 \%$, pendapatan keluarga $\geq$ Rp5.000.000 sebesar $89 \%$, dan memiliki tujuan bisnis sebesar $42 \%$. 
ISSN 2685-0605

\subsection{Total Operating Cost (TOC)}

Rekapitulasi nilai total operating cost maskapai penerbangan bertarif rendah dapat dilihat pada Tabel 4 .

Tabel 4 TOC Maskapai Penerbangan Bertarif Rendah

\begin{tabular}{ccc}
\hline No & \multicolumn{1}{c}{ Komponen Biaya } & Biaya per jam \\
\hline I & Biaya Operasi Langsung & \\
\cline { 2 - 3 } & Biaya Langsung Tetap & \\
\hline
\end{tabular}

Tabel 4 TOC Maskapai Penerbangan Bertarif Rendah

\begin{tabular}{llr}
\hline No Komponen Biaya & & Biaya per jam \\
\hline 1. Biaya penyusutan & $\mathrm{Rp}$ & $270,333.94$ \\
2. Biaya asuransi & $\mathrm{Rp}$ & $28,387.88$ \\
\hline 3. Biaya gaji tetap crew & $\mathrm{Rp}$ & $2,685.70$ \\
4. Biaya gaji tetap teknisi & $\mathrm{Rp}$ & 926.10 \\
5. Biaya crew training & $\mathrm{Rp}$ & 849.24 \\
\hline Biaya Langsung Variabel & & \\
6. Biaya pelumas & $\mathrm{Rp}$ & 94.00 \\
7. Biaya bahan bakar & $\mathrm{Rp}$ & $92,855.06$ \\
8. Biaya tunjangan crew & $\mathrm{Rp}$ & $4,630.52$ \\
9. Biaya overhaul/pemeliharaan & $\mathrm{Rp}$ & $26,857.03$ \\
10. Biaya jasa bandar udara & $\mathrm{Rp}$ & $4,787.07$ \\
1. Biaya jasa ground handling & $\mathrm{Rp}$ & $1,760.56$ \\
\hline Total biaya langsung & $\mathrm{Rp}$ & $434,167.11$ \\
\hline II & & \\
\hline Biaya Operasi Tidak Langsung & & \\
12. Biaya Organisasi & $\mathrm{Rp}$ & $5,788.15$ \\
13. Biaya pemasaran & $\mathrm{Rp}$ & $5,788.15$ \\
\hline Total biaya tidak langsung & $\mathrm{Rp}$ & $11,576.31$ \\
\hline Total Biaya Operasi Pesawat & $\mathrm{Rp}$ & $445,743.42$ \\
\hline
\end{tabular}

TOC penumpang per jam $=\mathrm{Rp} 445.743,42$

TOC per pnp per menit $=$ Rp7.429,06

Durasi prbgn rute Banda Aceh - Jakarta $=170$ menit

$\mathrm{TOC} / \mathrm{pnp}=\mathrm{TOC} / \mathrm{pnp}$ per mnt $\mathrm{x}$ durasi penerbangan $=\mathrm{Rp} 7.429,06 \times 170$

$=\mathrm{Rp} 1.262 .939,69$

Dibulatkan $=$ Rp1.263.000,00

Rekapitulasi nilai total operating cost maskapai penerbangan layanan penuh dapat dilihat pada Tabel 5 .

Tabel 5 TOC Maskapai Penerbangan Layanan Penuh

\begin{tabular}{clr}
\hline No Komponen Biaya & & Biaya per jam \\
\hline I & Biaya Operasi Langsung & \\
\cline { 2 - 3 } Biaya Langsung Tetap & & \\
1. Biaya penyusutan & $\mathrm{Rp}$ & $270,333.94$ \\
2. Biaya asuransi & $\mathrm{Rp}$ & $28,387.88$ \\
3. Biaya gaji tetap crew & $\mathrm{Rp}$ & $3,102.45$ \\
4. Biaya gaji tetap teknisi & $\mathrm{Rp}$ & 926.10 \\
5. Biaya crew training & $\mathrm{Rp}$ & 965.00 \\
\hline Biaya Langsung Variabel & & \\
6. Biaya pelumas & $\mathrm{Rp}$ & 114.59 \\
7. Biaya bahan bakar & $\mathrm{Rp}$ & $113,200.38$ \\
8. Biaya tunjangan crew & $\mathrm{Rp}$ & $5,556.63$ \\
9. Biaya overhaul/pemeliharaan $\mathrm{Rp}$ & $26,857.03$
\end{tabular}

10. Biaya jasa bandar udara $\quad \mathrm{Rp} \quad 5,851.16$

11. Biaya jasa ground handling $\mathrm{Rp} \quad 2,112.68$

12. Biaya catering $\quad \mathrm{Rp} \quad 80,000.00$

\begin{tabular}{lll}
\hline Total biaya langsung & $\mathrm{Rp}$ & $537,407.84$ \\
\hline
\end{tabular}

II Biaya Operasi Tidak Langsung

12. Biaya Organisasi $\quad \mathrm{Rp} \quad 5,788.15$

13. Biaya pemasaran $\quad \mathrm{Rp} \quad 5,788.15$

Total biaya tidak langsung $\quad \mathrm{Rp} \quad 11,576.31$

\begin{tabular}{lll} 
Total Biaya Operasi Pesawat & $\mathrm{Rp}$ & $548,984.15$ \\
\hline
\end{tabular}

TOC penumpang per jam $=\mathrm{Rp} 548.984,15$

TOC per pnp per menit $\quad=$ Rp9.149,74

Durasi pnrbgn rute Banda Aceh - Jakarta $=170$ menit

$\mathrm{TOC} / \mathrm{pnp}=\mathrm{TOC} / \mathrm{pnp}$ per menit $\mathrm{x}$ durasi penerbangan

$=\mathrm{Rp} 9.149,74 \times 170$

$=\mathrm{Rp} 1.555 .455,09$

Dibulatkan $=$ Rp1.556.000,00

\subsection{Ability To Pay (ATP)}

Dalam menghitung kemampuan membayar responden digunakan beberapa data yang diperoleh dari kuesioner yaitu penghasilan rata-rata penghasilan keluarga per tahun, rata-rata alokasi penghasilan pribadi untuk transportasi, rata-rata alokasi biaya transportasi untuk pengunaan pesawat terbang dan frekuensi perjalanan dengan menggunakan pesawat terbang setiap tahun. Data rekapitulasi hasil perhitungan ATP dapat dilihat di tabel 6 .

Tabel 6 Hasil Perhitungan ATP Responden Tiap Maskapai

\begin{tabular}{lcccccc}
\hline Mask & $\begin{array}{c}\text { Jum } \\
\text { Resp }\end{array}$ & $\begin{array}{c}\text { Rata-Rata } \\
\text { Jumlah } \\
\text { Pend/Thn }\end{array}$ & \multicolumn{2}{l}{$\begin{array}{c}\text { Rerata } \\
\text { \% Biaya Biaya Utk } \\
\text { Utk Trsp } \\
\text { Per Thn }\end{array}$} & $\begin{array}{c}\text { Resawat Per Thn } \\
\text { Prek }\end{array}$ & ATP \\
(Rp/pnp) & \\
\hline 1 & 2 & 4 & 6 & 7 & 8 & 9 \\
\hline Citilink & 45 & 136.400 .000 & 26,31 & 35,36 & 5,42 & 2.340 .455 \\
Lion & 95 & 106.623 .157 & 24,26 & 35,05 & 3,83 & 2.366 .490 \\
Batik & 39 & 117.692 .307 & 29,65 & 43,12 & 4,59 & 3.278 .912 \\
Garuda & 82 & 176.868 .292 & 28,02 & 38,05 & 6,09 & 3.098 .418 \\
\hline
\end{tabular}

Tabel 6 memperlihatkan bahwa kemampuan membayar tertinggi adalah responden maskapai Batik Air sebesar Rp3.279.000 dan kemampuan membayar responden terendah pada maskapai Citilink sebesar Rp2.341.000.

\subsection{Willingness To Pay (WTP)}

Keinginan membayar responden dipengaruhi oleh kualitas dan kuantitas jasa pesawat terbang, utilitas perjalanan, dan pendapatan pengguna. Hasil perhitungan rata-rata keinginan membayar respoden untuk setiap maskapai penerbangan dapat dilihat pada tabel 7 . 
ISSN 2685-0605

Tabel 7 Rata-Rata Keinginan Membayar Responden Setiap Maskapai

\begin{tabular}{lcccc}
\hline Maskapai & $\begin{array}{c}\text { Kemauan } \\
\text { Membayar }\end{array}$ & $\begin{array}{c}\text { Jumlah } \\
\text { Resp }\end{array}$ & WTP (Rp/pnp) \\
\hline \multicolumn{1}{c}{ 1 } & 2 & 3 & $4=(2 / 3)$ \\
\hline Citilink & Rp & 61.050 .000 & 45 & Rp 1.356.666,67 \\
Lion Air & Rp 130.025.000 & 95 & Rp 1.368,684,21 \\
Batik Air & Rp 64.446 .000 & 39 & Rp 1.652.461,54 \\
Garuda & Rp 135.450.000 & 82 & Rp 1.651.829,27 \\
Indonesia & &
\end{tabular}

Tabel 7 memperlihatkan bahwa keinginan membayar tertinggi adalah responden maskapai Batik Air sebesar Rp1.653.000 dan keinginan membayar responden terendah pada maskapai Citilink sebesar Rp1.357.000.

Tabel 8 Tabel Kesediaan Membayar Responden Semua Maskapai

\begin{tabular}{ccc}
\hline Tarif Yang Ingin Dibayarkan & Jumlah & Persentase \\
\hline$<1.000 .000$ & 17 & 7 \\
$1.000 .000-1.500 .000$ & 98 & 38 \\
$1.500 .001-2.000 .000$ & 100 & 38 \\
$2.000 .001-2.500 .000$ & 32 & 12 \\
$\geq 2.500 .000$ & 14 & 5 \\
\hline Total & 261 & 100 \\
\hline
\end{tabular}

Berdasarkan tabel 8 terlihat bahwa keinginan membayar responden dominan berada pada range Rp1.500.000 sampai dengan Rp2.000.000.

Besaran nilai tarif maskapai penerbangan menunjukkan kencenderungan nilai tarif ATP berada di atas tarif WTP, hal ini menggambarkan bahwa pengguna pesawat terbang merupakan kelompok choiced riders yang mempunyai penghasilan relatif tinggi tetapi memiliki keinginan membayar di bawah kemampuan membayar.

Berdasarkan penilaian kualitas pelayanan jasa pesawat terbang rute Banda Aceh - Jakarta dari responden maka didapatkan peringkat kualitas layanan dari yang terbaik adalah sistem pembelian tiket, jumlah tempat pembelian tiket dan tutur kata petugas bandara. Peningkatan prioritas pelayanan jasa yang perlu ditingkatkan agar responden ingin membayar lebih adalah ketepatan waktu keberangkatan dan kedatangan pesawat terbang rute Banda Aceh - Jakarta adalah keamanan dan keselamatan pesawat terbang rute Banda Aceh - Jakarta, dan petugas yang memiliki tutur kata yang sopan dan ramah.

Kesediaan untuk membayar lebih atas peningkatan prioritas pelayanan jasa maskapai pesawat disetujui oleh $52 \%$ responden. Dengan kisaran jumlah yang akan ditambahkan atas peningkatan prioritas pelayanan adalah sebesar Rp25.000 sampai dengan Rp250.000. Jumlah minimum yang ditambahkan responden adalah

Journal of The Civil Engineering Student Vol. 3. No. 1, April 2021, Halaman 22-28
Rp25.000, jumlah maksimum yang ditambahkan responden Rp1.000.000.

\section{Kesimpulan Dan Saran}

\subsection{Kesimpulan}

Berdasarkan data-data yang telah dikumpulkan, diolah dan dianalisis guna untuk menjawab tujuan dari penelitian ini, maka dapat disimpulkan bahwa:

1. Karakteristik responden yang dominan adalah pria sebesar 67\%, usia responden berkisar 30-39 tahun sebesar $31 \%$, status menikah sebanyak $73 \%$, pendapatan keluarga $\geq$ Rp5.000.000 sebesar 83\%, dan memiliki tujuan bisnis sebesar 33\%.

2. Besaran nilai tarif berdasarkan TOC maskapai penerbangan bertarif rendah dengan load factor yang diasumsikan 75\% adalah sebesar Rp1.263.000. Besaran nilai tarif berdasarkan TOC maskapai penerbangan layanan penuh dengan load factor yang diasumsikan 75\% adalah sebesar Rp1.556.000.

3. Besaran nilai tarif berdasarkan ATP pengguna pesawat Citilink sebesar Rp2.341.000; ATP pengguna pesawat Lion Air sebesar Rp2.367.000; ATP pengguna pesawat Batik Air sebesar Rp3.279.000; dan ATP pengguna pesawat Garuda Indonesia sebesar Rp3.099.000.

4. Besaran nilai tarif berdasarkan WTP pengguna pesawat Citilink sebesar Rp1.357.000; WTP pengguna pesawat Lion Air sebesar Rp1.369.000; WTP pengguna pesawat Batik Air sebesar Rp1.653.000; dan WTP pengguna pesawat Garuda Indonesia sebesar Rp1.652.000.

5. Besaran nilai tarif maskapai penerbangan menunjukkan kencenderungan nilai tarif ATP berada di atas tarif WTP, hal ini menggambarkan bahwa pengguna pesawat terbang merupakan kelompok choiced riders yang mempunyai penghasilan relatif tinggi tetapi memiliki keinginan membayar di bawah kemampuan membayar.

6. Kesediaan untuk membayar lebih atas peningkatan prioritas pelayanan jasa maskapai pesawat disetujui oleh 52\% responden. Dengan rata-rata jumlah yang akan ditambahkan atas peningkatan prioritas pelayanan adalah sebesar Rp249.333,33.

7. Peningkatan prioritas pelayanan jasa yang perlu ditingkatkan agar responden ingin membayar lebih adalah ketepatan waktu keberangkatan dan kedatangan pesawat terbang rute Banda Aceh Jakarta adalah keamanan dan keselamatan pesawat terbang rute Banda Aceh - Jakarta, dan petugas yang memiliki tutur kata yang sopan dan ramah.

\subsection{Saran}

1. Maskapai penerbangan harus mengoptimalkan kinerja pelayanan sehingga dapat menaikkan nilai tarif WTP pengguna jasa. 
2. Dapat dilakukan penelitian selanjutnya untuk memperhitungkan nilai TOC untuk rute lainnya dengan nilai load factor yang berbeda.

3. Penelitian selajutnya diharapkan menggunakan skenario tarif.

\section{Daftar Kepustakaan}

[1] Keputusan Menteri Perhubungan Republik Indonesia: Nomor 72 Tahun 2019, Tarif Batas Atas Penumpang Pelayanan Kelas Ekonomi Angkutan Udara Niaga Berjadwal Dalam Negeri, Jakarta.

[2] Peraturan Menteri Perhubungan Republik Indonesia: Nomor PM 20 Tahun 2019, Tata Cara dan Formulasi Perhitungan Tarif Batas Atas Penumpang Pelayanan Kelas Ekonomi Angkutan Udara Niaga Berjadwal Dalam Negeri, Jakarta.

[3] Julien, Analisis Ability To Pay Dan Willingness To Pay Pengguna Jasa Kereta Api Bandara Kuala Namu, Fakultas Ekonomi, Universitas Sumatera Utara, Medan, 2014.

[4] M. R. Permata, Rahmad, Analisa Ability To Pay dan Willingness To Pay Pengguna Jasa Kereta Api Bandara Soekarno Hatta-Manggarai, Universitas Indonesia, Jakarta, 2012.

[5] R. Lupiyoadi, Manajemen Pemasaran Jasa, Edisi 3, Salemba, Jakarta, 2014.

[6] S. Arikunto, Prosedur Penelitian Suatu Pendekatan Praktik, Rineka Cipta, Jakarta, 2010. 